\title{
Functional Reorganization of the Motor Cortex in Adult Rats after Cortical Lesion and Treatment with Monoclonal Antibody IN-1
}

\author{
April J. Emerick, ${ }^{1,2}$ Edward J. Neafsey, ${ }^{2,4}$ Martin E. Schwab, ${ }^{5,6}$ and Gwendolyn L. Kartje ${ }^{1,2,3,4}$ \\ ${ }^{1}$ Research and Neurology Service, Edward Hines Veterans Affairs Hospital, Hines, Illinois 60141, ${ }^{2}$ Neuroscience Program and Departments of ${ }^{3}$ Neurology \\ and ${ }^{4}$ Cell Biology, Neurobiology, and Anatomy, Loyola University Medical Center, Maywood, Illinois 60153, and ${ }^{5}$ Brain Research Institute, University of \\ Zurich, and ${ }^{6}$ Department of Biology, Swiss Federal Institute of Technology, Zurich, CH-8057 Switzerland
}

We previously reported anatomical plasticity in the adult motor cortex after a unilateral sensorimotor cortex (SMC) lesion and treatment with monoclonal antibody $(\mathrm{mAb}) \mathrm{IN}-1$, which permits neurite outgrowth from the intact, opposite cortex into deafferented subcortical targets. This study was designed to investigate whether treatment with the mAb IN-1 after SMC lesion in the adult leads to functional reorganization of the intact, opposite motor cortex. Adult rats underwent unilateral SMC aspiration lesion and treatment with either $\mathrm{mAb}$ IN-1 or control antibody, or no treatment. After a 6 week survival period, the intact, opposite forelimb motor cortex was explored using intracortical microstimulation to evoke forelimb movements. A dramatic increase in ipsilateral movements of the lesion-impaired forelimb was found in animals treated with $\mathrm{mAb}$ IN-1 compared with control animals. These results resembled our previous findings of cortical reorganization in the spared hemisphere after neonatal cortical lesion and without any additional treatment. These results show that, after adult cortical lesion, treatment with mAb IN-1 induces a functional reorganization of the intact, opposite motor cortex.

Key words: motor cortex; intracortical microstimulation; Nogo-A; corticospinal tract; cortical injury; plasticity

\section{Introduction}

Contrary to conditions during development, the mature CNS has less capacity to form new neuronal connections after injury. Such new connections (i.e., anatomical plasticity) may be the underlying substrate for the substantial functional recovery often seen after lesion in the young (for review, see Kolb and Whishaw, 1989). One explanation for the decreased amount of anatomical plasticity after adult CNS injury is the presence of myelinassociated inhibitory factors that block neurite outgrowth (Schwab, 2002). One such factor is Nogo-A, a protein product of the Nogo gene (Chen et al., 2000; GrandPré et al., 2000; Prinjha et al., 2000), which is expressed at the cell surface of oligodendrocytes (Oertle et al., 2003). Application of anti-Nogo-A antibodies in the normal adult results in transient axonal outgrowth in cerebellar Purkinje cells (Buffo et al., 2000) and corticospinal neurons, concomitantly with the upregulation of several growthrelated proteins and growth factors (Bareyre et al., 2002). Nogo-A and one of its receptors, Nogo-66 receptor (NgR), are juxtaposed along myelinated axons in the adult (Wang et al., 2002), and NgR blockade results in sustained axonal outgrowth in the corticospinal tract (CST) after spinal cord lesions (GrandPré et al., 2002).

Our previous work has shown that treatment with the monoclonal antibody (mAb) IN-1 raised against NI-250 (later renamed Nogo-A) after cortical lesions in adult rats results in the

\footnotetext{
Received Dec. 5, 2002; revised April 17, 2003; accepted April 23, 2003.

This work was supported by the Department of Veterans Affairs (DVA) and a DVA Career Development Award (G.L.K.), the Swiss National Science Foundation, and National Institutes of Health Grant NS 40960. We thank Melanie Bollnow for her excellent technical support.

Correspondence should be addressed to Dr. April Emerick, Edward Hines Veterans Affairs Hospital, Research Service 151, Hines, IL 60141. E-mail: aemeric@lumc.edu.

Copyright $\odot 2003$ Society for Neuroscience $\quad$ 0270-6474/03/234826-05\$15.00/0
}

formation of new corticoefferent connections from the intact, opposite cortex to the deafferented striatum (Kartje et al., 1999), red nucleus (Wenk et al., 1999; Papadopoulos et al., 2002), and basilar pontine nuclei (Wenk et al., 1999). Those results were strikingly similar to anatomical results found after neonatal cortical lesions with no treatment, in which the intact, opposite motor cortex sends projections to the deafferented striatum (Kolb et al., 1992, 1994), red nucleus (Leong and Lund, 1973; Nah and Leong, 1976; Naus et al., 1985, 1986; Murakami and Higashi, 1988), basilar pontine nuclei (Leong and Lund, 1973; Castro and Mihailoff, 1983; Kartje-Tillotson et al., 1986), and spinal cord gray matter (Hicks and D'Amato, 1970; Leong and Lund, 1973; Castro, 1975; Leong, 1976; Whishaw and Kolb, 1988; Barth and Stanfield, 1990; Kuang and Kalil, 1990; Rouiller et al., 1991).

In support of the functional role of the anatomical plasticity reported after neonatal lesions, electrophysiological studies showed that neonatal cortical lesions also result in a reorganization of the intact, opposite cortex (Kartje-Tillotson et al., 1985, 1987). In this work, low-current microstimulation in the unablated opposite motor cortex elicited movement of the lesionimpaired forelimb, thereby indicating new functional connections that could compensate for lost motor input.

The purpose of the present study was to investigate the possibility of functional reorganization of the motor cortex after adult cortical lesion when treated with mAb IN-1. Accordingly, reorganization of the intact, opposite motor cortex was observed in animals with sensorimotor cortex (SMC) lesion and mAb IN-1 treatment that corresponded to an increase in movements of the lesion-impaired forelimb, similar to previous findings after neocortical lesions with no treatment. 


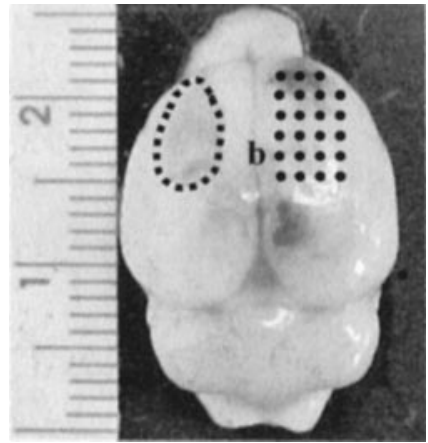

Figure 1. Dorsal view of a rat brain 6 weeks after aspiration lesion surgery and mAb IN-1 treatment. The typical size and location of an aspiration lesion cavity is outlined in the left hemisphere (dotted line). The points on the right hemisphere indicate the area of intracortical microstimulation. The ruler indicates millimeter increments; b, bregma landmark.

\section{Materials and Methods}

Animals. All of the animal procedures were approved by the Joint Institutional Animal Care and Use Committee of Loyola University and Hines Veterans Affairs Hospital. Eighteen male Long-Evans blackhooded rats at $8-10$ weeks of age were divided into the following four experimental groups: (1) SMC lesion plus mAb IN-1 $(n=6)$, (2) SMC lesion plus control Ab $(n=4),(3)$ SMC lesion only $(n=4)$, and (4) normal $(n=4)$.

Sensorimotor aspiration lesion. Animals were anesthetized with sodium pentobarbital (50 mg/kg, i.p.) supplemented with ketamine $(40 \mathrm{mg} / \mathrm{kg}$, i.m.) as needed. Anesthetized animals were then secured in a stereotaxic frame, and the scalp was incised along the midline. With the bregma as a landmark, the skull was opened to expose the left sensorimotor cortex, and the forelimb and hindlimb motor cortex was aspirated with gentle suction using the following coordinates: $4.0 \mathrm{~mm}$ rostral, $2.0 \mathrm{~mm}$ caudal, $1.0 \mathrm{~mm}$ medial, and $4.0 \mathrm{~mm}$ lateral to bregma (Neafsey et al., 1986).

Antibody application. Immediately after cortical aspiration lesion and while animals were still anesthetized, mouse hybridoma cells $\left(1 \times 10^{5}\right.$ cells in $1 \mu \mathrm{l}$ ) secreting either mAb IN-1 or control antibody (anti-HRP) were delivered by Hamilton syringe posterior to the lesion site into the hippocampus ( $4.0 \mathrm{~mm}$ caudal, $5.0 \mathrm{~mm}$ lateral, and $5.0 \mathrm{~mm}$ ventral to bregma). Previous work has shown that application of the hybridoma secreting cells near the lateral ventricle results in the secretion of antibody into the CSF and diffusion throughout the brain (Thallmair et al., 1998; Z'Graggen et al., 1998; Kartje et al., 1999; Wenk et al., 1999; Raineteau et al., 2001; Papadopoulos et al., 2002). All of the animals, including control animals, received daily injections of cyclosporin A (10 mg/kg, i.p.) $1 \mathrm{~d}$ before and $7 \mathrm{~d}$ after surgery to suppress host rejection of the mouse hybridoma cells. Animals were returned to standard housing conditions.

Intracortical microstimulation mapping of forelimb motor cortex. Six weeks after SMC lesion, animals underwent intracortical microstimulation (ICMS) for cortical mapping as described previously (Neafsey et al., 1986; Z'Graggen et al., 2000). Animals were reanesthetized with ketamine $(100 \mathrm{mg} / \mathrm{kg}$, i.m.) and xylazine $(5 \mathrm{mg} / \mathrm{kg}$, i.p.) with supplemental doses of ketamine (20 mg/kg, i.m.; given as needed). They were secured in a stereotaxic frame while resting on a heating pad set to $37^{\circ} \mathrm{C}$. The forelimbs and shoulders were shaved to better facilitate observation of movements. Before opening the skull, the cisterna magna was opened and drained to reduce swelling of the cortex. Using a dental drill and rongeurs, the skull overlaying the right, nonlesioned SMC was removed, the dura was opened, and the brain was kept moist with warm mineral oil. Using bregma as a cranial landmark, the motor forelimb area (Fig. 1) was explored in $0.25-0.5 \mathrm{~mm}$ steps with a stimulating electrode (a sharpened, glass-insulated tungsten wire with a noninsulated tip length of 100 $\mu \mathrm{m})$. The stimulation current $(2-80 \mu \mathrm{A})$ was applied as a $300 \mathrm{msec}$ train of $0.25 \mathrm{msec}$ pulses at $350 \mathrm{~Hz}$ with an electrode depth of $1.7 \mathrm{~mm}$ below the cortical pial surface. Stimulus currents were monitored on an oscilloscope by measuring the voltage drop across a $10 \mathrm{k} \Omega$ resistor. One investigator applied stimulation current, while another investigator blinded to the experimental group observed movements.
For each animal, a map of the SMC was generated, demonstrating the topographical organization of forelimb movements at threshold stimulating currents. The area of the forelimb cortex was mapped to its rostralcaudal and medial-lateral borders as defined by previous mapping experiments (Neafsey et al., 1986). All of the cortical points were screened for movements at $80 \mu \mathrm{A}$, and the current threshold was determined as the lowest current necessary to reliably produce a visible movement. When a forelimb movement was observed, the current threshold was recorded for the contralateral limb first and the ipsilateral, lesionimpaired limb second (if present), along with the type of movement elicited. All of the forelimb movements were grouped into two categories: distal (digit or wrist) and proximal (elbow or shoulder). Individual forelimb motor maps from each animal were then combined to make a representative map for each experimental group.

\section{Results}

In animals from all of the groups, forelimb movements were elicited from cortical areas consistent with the caudal forelimb motor cortex described previously (Neafsey et al., 1986). Stimulation of the cortex surrounding the forelimb region elicited various types of movements: tongue, jaw, and nose (rostrally); hip, ankle, toe, and tail (caudally); and vibrissas (medially). The lateral border was characterized by a lack of observed movements, even at higher thresholds, indicating stimulation of the sensory cortex. The area of forelimb maps for all of the groups was in a consistent location: between $4.0 \mathrm{~mm}$ anterior and $0.5 \mathrm{~mm}$ posterior to bregma and between 1.5 and $4.0 \mathrm{~mm}$ lateral to bregma. Therefore, there was no shift in forelimb boundaries between animal groups.

In normal animals, ICMS of the forelimb motor cortex at stimulation threshold resulted primarily in contralateral movements (46 responsive stimulation sites), with few ipsilateral movements (6 responsive stimulation sites) (Fig. 2). Ipsilateral movements were not evoked without a contralateral movement at the same cortical point. Similar findings occurred in animals with lesion or lesion plus control antibody (Fig. 2) in which ICMS at stimulation threshold evoked mostly contralateral movements (lesion only, 55 responsive stimulation sites; lesion plus control antibody, 91 responsive stimulation sites) with only a few ipsilateral movements (lesion only, 13 responsive stimulation sites; lesion plus control antibody, 14 responsive stimulation sites). In marked contrast, animals sustaining SMC lesion plus mAb IN-1 treatment showed a dramatic increase in ipsilateral forelimb movements (81 responsive stimulation sites) evoked from the intact, opposite cortex in addition to the presence of evoked contralateral movements (132 responsive stimulation sites) (Fig. 2). Additional statistical analysis (Fig. 3) showed a significant increase in the percentage of stimulation points that evoked ipsilateral movements in the SMC lesion plus mAb IN-1 treatment group in comparison with that of normals, the SMC lesion-only group, and SMC lesion plus control antibody group $(p<0.001$; one-way ANOVA with Bonferroni post test). There was no statistical difference between the percentage of ipsilateral forelimb movements in other treatment groups.

Contralateral forelimb movements were evoked at low thresholds (13-16 $\mu \mathrm{A})$ in all of the groups, with no statistical difference in the average current threshold for evoked contralateral movements (data not shown). Ipsilateral forelimb movements were evoked at slightly higher current thresholds $(27-31 \mu \mathrm{A})$ in all of the experimental groups ( $p>0.01$; unpaired $t$ test), and there was no statistical difference when comparing the average ipsilateral current threshold among experimental groups (data not shown). Additionally, there was no apparent difference in the 

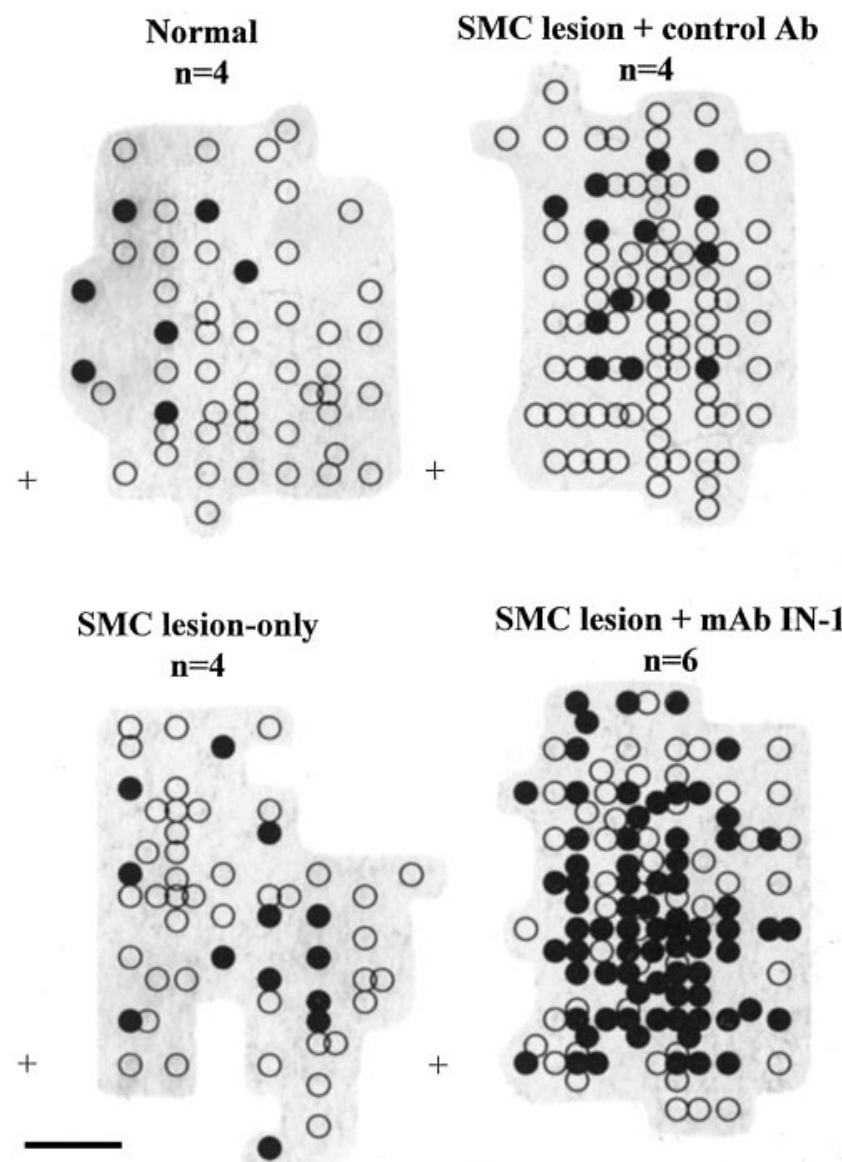

Figure 2. Individual ICMS forelimb maps were combined into representative forelimb maps in the four experimental groups. Points indicate the stereotaxic coordinates at which forelimb movements were evoked with stimulating current at threshold values. Movements in the ipsilateral, lesion-affected forelimb were always evoked in the presence of contralateral movements. Open circles represent contralateral movements alone, and filled circles represent ipsilateral plus contralateral movements. The plus signs represent reference coordinates: $0.0 \mathrm{~mm}$ rostral and $0.5 \mathrm{~mm}$ lateral to bregma. Shaded gray areas represent the boundaries of the forelimb maps. Scale bar, $1 \mathrm{~mm}$. Ab, Antibody.

relative responsiveness of the nonlesioned SMC among experimental groups (data not shown).

We next examined the distribution of proximal and distal evoked forelimb movements. In the contralateral forelimb, nearly an equal proportion of proximal and distal movements were evoked in all of the experimental groups (data not shown). In the ipsilateral forelimb, however, proximal movements were significantly greater than distal movements in all of the experimental groups ( $p<0.01$; one-way ANOVA) (Fig. 4). There was no statistical difference, however, when comparing the categories of movements ( $p>0.05$; one-way ANOVA). Thus, although treatment with $\mathrm{mAb}$ IN-1 did increase the frequency of evoked ipsilateral movements, it did not change the types of movements.

\section{Discussion}

This study demonstrates that intracerebral application of $\mathrm{mAb}$ IN-1 results in cortical reorganization of the intact, opposite motor cortex after SMC lesion in adult rats. ICMS mapping of the motor cortex in the hemisphere opposite to the lesion revealed a dramatic increase in ipsilateral movements in the lesionimpaired forelimb compared with control groups.

Recent clinical reports indicate that, after adult brain damage, the motor cortex is capable of reorganizing. In recovered stroke

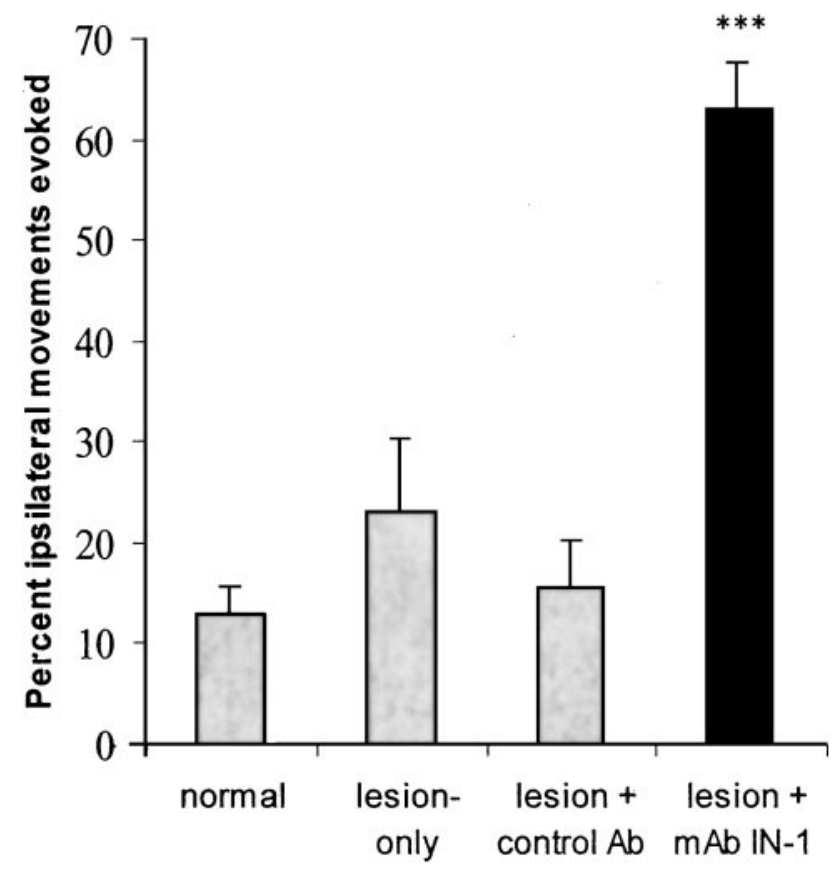

Figure 3. Treatment with $\mathrm{mAb} I \mathrm{~N}-1$ after SMC lesions (filled bar) significantly increased ipsilateral output from the nonlesioned motor cortex when compared with all other groups (gray bars). Percentage values represent the average number of ipsilateral points/total forelimb points. Error bars indicate mean \pm SEM. Asterisks indicate significance compared with all of the groups: ${ }^{* * *} p<0.001$, one-way ANOVA, post hoc Bonferroni's multiple comparison. Ab, Antibody.

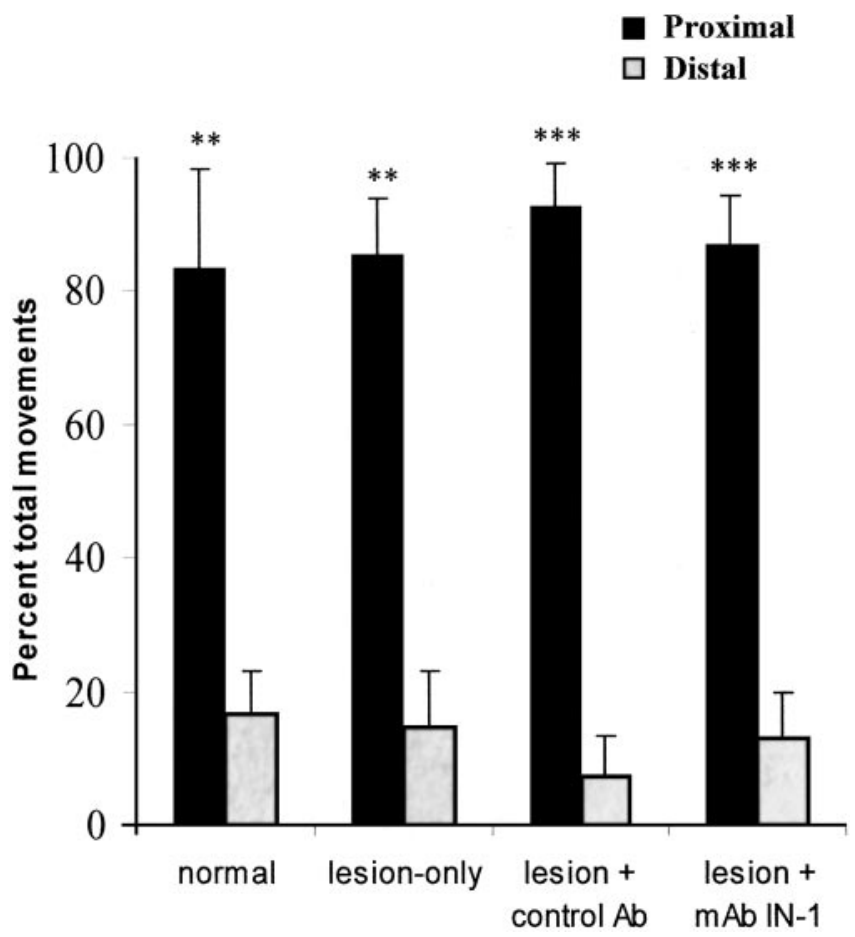

Figure 4. Treatment with $\mathrm{mAb} I \mathrm{~N}-1$ after SMC lesions did not affect the characteristics of proximal (filled bars) and distal (gray bars) movements in the ipsilateral forelimb. There was a significantly greater percentage of proximal compared with distal movements in the forelimb in all of the treatment groups. There was no statistical difference between the $\mathrm{mAb}$ IN-1 treatment and the control groups $(p>0.05)$. Error bars indicate mean \pm SEM. Asterisks indicate significance compared with ipsilateral distal movements within each group: ${ }^{* *} p<0.01$, ${ }^{* *} p<$ 0.001 , one-way ANOVA, post hoc Bonferroni's multiple comparison. Ab, Antibody. 
patients, several studies have reported an increase in motor cortical activity in the nonstroke hemisphere during movement of the ipsilateral, stroke-affected hand, suggesting that the nondamaged hemisphere plays an important role in recovery (for review, see Cramer, 1999). Recent studies have shown that bilateral activation of the motor cortex occurs with unilateral hand movements in patients with nondisabling multiple sclerosis and that such adaptive responses might be important for maintaining motor function after cortical damage (Lee et al., 2000; Reddy et al., 2000; Rocca et al., 2002). Studies in animals have also shown that the adult motor cortex is capable of some functional reorganization, and such cortical changes might contribute to the limited spontaneous recovery observed after injury (for review, see Nudo et al., 2001). In the rodent, the sensorimotor cortex reorganizes in response to motor nerve injury (Donoghue et al., 1990), forelimb amputation (Sanes et al., 1990), and partial spinal cord injury (Fouad et al., 2001). Abo et al. (2001) observed that increased functional magnetic resonance imaging activity in the nonstroke hemisphere contributes to the spontaneous recovery of hindlimb function after ischemic stroke in rats. Additional behavioral studies are needed to evaluate whether such new connections contribute to the recovery of limb use.

Our results confirm previous reports that a small, but functional, pathway exists for ipsilateral forelimb movements in the normal adult rat (Kartje-Tillotson et al., 1985, 1987). In animals treated with mAb IN-1 after cortical injury, an increase was found in the ipsilateral forelimb movements without any changes in the current thresholds or types of movements. These results indicate that mAb IN-1 treatment might result in the expansion or strengthening of a preexisting neuroanatomical pathway that contributes to ipsilateral movements, such as the ipsilateral dorsal or ventral CSTs (Brösamle and Schwab, 2000). The motor cortex might also mediate control of the ipsilateral forelimb through the remodeling of other descending motor tracts including the crossed CST or the rubrospinal tract. We reported previously that mAb IN-1 treatment leads to increased corticoefferent projections from the intact cortex to the deafferented red nucleus after cortical aspiration lesions (Wenk et al., 1999) and stroke (Papadopoulos et al., 2002), thereby restoring cortical input to the rubrospinal system in the damaged hemisphere and possibly contributing to the observed recovery from motor impairments after stroke. Wiessner et al. $(2002,2003)$ have also reported that treatment with a different antibody against Nogo-A after ischemic stroke induces significant axonal outgrowth from the crossed CST into the deafferented spinal cord correlated with improved behavioral outcome. We are currently investigating which pathways might be mediating ipsilateral forelimb movements in animals treated with mAb IN-1 after SMC lesions.

Another important result from this study is that the lesion alone does not increase ipsilateral forelimb movements or alter the characteristics of the forelimb map. The lack of lesioninduced changes in the opposite cortex is not surprising, because others have reported previously that aspiration lesion alone does not result in anatomical plasticity in the adult (Napieralski et al., 1996; Uryu et al., 2001), nor is there any slow-wave neural activity that might be associated with axonal outgrowth (Carmichael and Chesselet, 2002). Furthermore, there is no change in the expression of molecules associated with neuronal growth after aspiration lesions (Szele et al., 1995). However, treatment with mAb IN-1 after CST lesions has been shown to induce the upregulation of growth factors (brain-derived neurotrophic factor and vascular endothelial growth factor) and growth-associated proteins (actin, myosin, and GAP-43) and results in the enhanced expres- sion of axonal guidance molecules (semaphorins and slits) and neurotrophic factors (insulin-like growth factor and bone morphogenic protein) (Bareyre et al., 2002). These changes in gene expression were found concomitantly with significant axonal outgrowth from the intact CST into deafferented spinal cord areas. Treatment with $\mathrm{mAb}$ IN-1 after SMC lesions might also result in such changes in gene expression and contribute to the observed functional reorganization in the motor cortex.

We and others have shown that treatment with either $\mathrm{mAb}$ IN-1 or other anti Nogo-A antibodies after adult cortical lesions (Kartje et al., 1999; Wenk et al., 1999; Papadopoulos et al., 2002; Wiessner et al., 2002, 2003) or CST lesions (Bregman et al., 1995; Thallmair et al., 1998; Z'Graggen et al., 1998; Brösamle et al., 2000; Merkler et al., 2001; Raineteau et al., 2001) results in neuroanatomical plasticity and/or neuronal regeneration correlated with behavioral recovery. In support of these neuroanatomical and behavioral results, this study provides evidence that $\mathrm{mAb}$ IN-1 (i.e., Nogo-A blockade) after adult cortical injury results in a physiological reorganization of the motor cortex that is functionally meaningful. This observed functional reorganization could be important for recovery of motor control after cortical damage resulting from stroke, traumatic brain injury, multiple sclerosis, or spinal cord injury.

\section{References}

Abo M, Chen Z, Lai LJ, Reese T, Bjelke B (2001) Functional recovery after brain lesion-contralateral neuromodulation: an fMRI study. NeuroReport 12:1543-1547.

Bareyre FM, Haudenschild B, Schwab ME (2002) Long-lasting sprouting and gene expression changes induced by the monoclonal antibody IN-1 in the adult spinal cord. J Neurosci 22:7097-7110.

Barth TM, Stanfield BB (1990) The recovery of forelimb-placing behavior in rats with neonatal unilateral cortical damage involves the remaining hemisphere. J Neurosci 10:3449-3459.

Bregman BS, Kunkel-Bagden E, Schnell L, Dai HN, Gao D, Schwab ME (1995) Recovery from spinal cord injury mediated by antibodies to neurite growth inhibitors. Nature 378:498-501.

Brösamle C, Schwab ME (2000) Ipsilateral, ventral corticospinal tract of the adult rat: ultrastructure, myelination and synaptic connections. J Neurocytol 29:499-507.

Brösamle C, Huber AB, Fiedler M, Skerra A, Schwab ME (2000) Regeneration of lesioned corticospinal tract fibers in the adult rat induced by a recombinant, humanized IN-1 antibody fragment. J Neurosci 20:8061-8068

Buffo A, Zagrebelsky M, Huber AB, Skerra A, Schwab ME, Strata P, Rossi F (2000) Application of neutralizing antibodies against NI-35/250 myelinassociated neurite outgrowth inhibitory proteins to the adult rat cerebellum induces sprouting of uninjured Purkinje cell axons. J Neurosci 20:2275-2286.

Carmichael ST, Chesselet M-F (2002) Synchronous neuronal activity is a signal for axonal sprouting after cortical lesions in the adult. J Neurosci 22:6042-6070.

Castro AJ (1975) Ipsilateral corticospinal projection after large cerebral lesion in neonatal rats. Exp Neurol 46:1-8.

Castro AJ, Mihailoff GA (1983) Corticopontine remodelling after cortical and/or cerebellar lesions in newborn rats. J Comp Neurol 219:112-123.

Chen MS, Huber AB, van der Haar ME, Frank M, Schnell L, Spillmann AA, Christ F, Schwab ME (2000) Nogo-A is a myelin-associated neurite outgrowth inhibitor and an antigen for monoclonal antibody IN-1. Nature 403:434-439.

Cramer SC (1999) Stroke recovery: lessons from functional MR imaging and other methods of human brain mapping. Phys Med Rehabil Clin N Am 10:875-886.

Donoghue JP, Suner S, Sanes JN (1990) Dynamic organization of primary motor cortex output to target muscles in adult rats. II. Rapid reorganization following motor nerve lesions. Exp Brain Res 70:492-503.

Fouad K, Pedersen V, Schwab ME, Brösamle C (2001) Cervical sprouting of corticospinal fibers after thoracic spinal cord injury accompanies shifts in evoked motor responses. Curr Biol 11:1766-1770. 
GrandPré T, Nakamura F, Vartanian T, Strittmatter SM (2000) Identification of Nogo inhibitor of axon regeneration as a reticulon protein. Nature 403:439-444.

GrandPré T, Li S, Strittmatter SM (2002) Nogo-66 receptor antagonist peptide promotes axonal regeneration. Nature 417:547-551.

Hicks SP, D’Amato CJ (1970) Motor-sensory and visual behavior after hemispherectomy in newborn and mature rats. Exp Neurol 29:416-438.

Kartje GL, Schulz MK, Lopez-Yunez A, Schnell L, Schwab ME (1999) Corticostriatal plasticity is restricted by myelin-associated neurite growth inhibitors in the adult rat. Ann Neurol 45:778-786.

Kartje-Tillotson G, Neafsey EJ, Castro AJ (1985) Electrophysiological analysis of motor cortical plasticity after cortical lesions in newborn rats. Brain Res 332:103-111.

Kartje-Tillotson G, Neafsey EJ, Castro AJ (1986) Topography of corticopontine remodeling after cortical lesions in newborn rats. J Comp Neurol 250:206-214

Kartje-Tillotson G, O’Donoghue DL, Dauzvardis MF, Castro AJ (1987) Pyramidotomy abolishes the abnormal movements evoked by intracortical microstimulation in adult rats that sustained neonatal cortical lesions. Brain Res 415:172-177.

Kolb B, Whishaw IQ (1989) Plasticity in the neocortex: mechanisms underlying recovery from early brain damage. Prog Neurobiol 32:235-276.

Kolb B, Gibb R, van der Kooy D (1992) Cortical and striatal structure and connectivity are altered by neonatal hemidecortication in rats. J Comp Neurol 322:311-324.

Kolb B, Gibb R, van der Kooy D (1994) Neonatal frontal cortical lesions in rats alter cortical structure and connectivity. Brain Res 62:85-97.

Kuang RZ, Kalil K (1990) Specificity of corticospinal axon arbors sprouting into denervated contralateral spinal cord. J Comp Neurol 244:163-173.

Lee M, Reddy H, Johansen-Berg H, Pendlebury S, Jencinson M, Smith S, Palace J, Matthews PM (2000) The motor cortex shows adaptive functional changes to brain injury from multiple sclerosis. Ann Neurol 47:606-613.

Leong SK (1976) A qualitative electron microscopic investigation of the anomalous corticofugal projections following neonatal lesions in the albino rats. Brain Res 107:1-8.

Leong SK, Lund RD (1973) Anomalous bilateral corticofugal pathways in albino rats after neonatal lesions. Brain Res 62:218-221.

Merkler D, Metz GAS, Raineteau O, Dietz V, Schwab ME, Fouad K (2001) Locomotor recovery in spinal cord injured rats treated with an antibody neutralizing the myelin-associated neurite growth inhibitor Nogo-A. J Neurosci 21:3665-3673.

Murakami F, Higashi S (1988) Presence of crossed corticorubral fibers and increase of crossed projections after unilateral lesions of the cerebral cortex of the kitten: a demonstration using anterograde transport of Phaseolus vulgaris leucoagglutin. Brain Res 447:98-108.

Nah SH, Leong SK (1976) Bilateral corticofugal projections to the red nucleus after neonatal lesions in the albino rat. Brain Res 107:433-436.

Napieralski JA, Butler AK, Chesselet M-F (1996) Anatomical and functional evidence for lesion-specific sprouting of corticostriatal input in the adult rat. J Comp Neurol 373:484-497.

Naus CG, Flumerfelt BA, Hrycyshyn AW (1985) An HRP-TMB ultrastructural study of rubral afferents in the rat. J Comp Neurol 239:453-465.

Naus CG, Flumerfelt BA, Hrycyshyn AW (1986) Contralateral corticorubral fibers induced by neonatal lesions are not collaterals of the normal ipsilateral projections. Neurosci Lett 70:52-58.

Neafsey EJ, Bold EL, Haas G, Hurley-Gius KM, Quirk G, Sievert CF, Terreberry RR (1986) The organization of the rat motor cortex: a microstimulation mapping study. Brain Res Rev 11:77-96.

Nudo RJ, Plautz EJ, Frost SB (2001) Role of adaptive plasticity in recovery of function after damage to motor cortex. Muscle Nerve 24:1000-1019.

Oertle T, van der Haar ME, Bandtlow CE, Robeva A, Burfeind P, Buss A, Huber AB, Simonen M, Schnell L, Brösamle C, Kaupmann K, Vallon R, Schwab ME (2003) Nogo-A inhibits neurite outgrowth and cell spreading with three discrete regions. J Neurosci, in press.
Papadopoulos CM, Tsai S-Y, Alsbiei T, O’Brien TE, Schwab ME, Kartje GL (2002) Functional recovery and neuroanatomical plasticity following middle cerebral artery occlusion and IN-1 antibody treatment in the adult rat. Ann Neurol 51:433-441.

Prinjha R, Moore SE, Vinson M, Blake S, Morrow R, Christie G, Michalovich D, Simmons DL, Walsh FS (2000) Inhibitor of neurite outgrowth in humans. Nature 403:383-384.

Raineteau O, Fouad K, Noth P, Thallmair M, Schwab ME (2001) Functional switch between motor tracts in the presence of the mAb IN-1 in the adult rat. Proc Natl Acad Sci USA 98:6929-6934.

Reddy H, Narayanan S, Arnoutelis R, Jenkinson M, Antel J, Mathews PM, Arnold DL (2000) Evidence for adaptive functional changes in the cerebral cortex with axonal injury from multiple sclerosis. Brain 123:2314-2320.

Rocca MA, Falini A, Colombo B, Scotti G, Comi G, Filippi M (2002) Adaptive functional changes in the cerebral cortex of patients with nondisabling multiple sclerosis correlate with the extent of brain structural damage. Ann Neurol 51:330-339.

Rouiller EM, Fengyi L, Moret V, Wiesendanger M (1991) Trajectory of redirected corticospinal axons after unilateral lesion of the sensorimotor cortex in neonatal rat; a Phaseolu vulgaris leucoagglutin (PHA-L) tracing study. Exp Neurol 114:53-65.

Sanes JN, Suner S, Donoghue JP (1990) Dynamic organization of primary motor cortex output to target muscles in adult rats. I. Long-term patterns of reorganization following motor or mixed peripheral nerve lesions. Exp Brain Res 79:479-491.

Schwab ME (2002) Repairing the injured spinal cord. Science 295:1029-1031.

Szele FG, Alexander C, Chesselet M-F (1995) Expression of molecules associated with neuronal plasticity after aspiration and thermocoagulatory lesions of the cerebral cortex in adult rats. J Neurosci 15:4429-4448.

Thallmair M, Metz GAS, Z'Graggen WJ, Raineteau O, Kartje GL, Schwab ME (1998) Neurite growth inhibitors restrict structural plasticity and functional recovery following corticospinal tract lesions. Nat Neurosci 1:124-131.

Uryu K, MacKenzie L, Chesselet M-F (2001) Ultrastructural evidence for differential axonal sprouting in the striatum after thermocoagulatory and aspiration lesions of the cerebral cortex in adult rats. Neuroscience 105:307-316.

Wang X, Chun SH, Treloar H, Vartanian T, Greer CA, Strittmatter SM (2002) Localization of Nogo-A and Nogo-66 receptor proteins at sites of axon-myelin and synaptic contact. J Neurosci 22:5505-5515.

Wenk CA, Thallmair M, Kartje GL, Schwab ME (1999) Increased corticofugal plasticity after unilateral cortical lesions combined with neutralization of the IN-1 antigen in adult rats. J Comp Neurol 410:143-157.

Wiessner C, Kartje GL, Hillenbrand R, Mir AK, Schwab ME (2002) AntiNogo-A antibody therapy after experimental stroke. In: Pharmacology of cerebral ischemia (Krieglstein J, Klumpp S, eds), pp 343-354. Stuttgart, Germany: Medpharm Scientific.

Wiessner C, Bareyre FM, Ballegrini PR, Mir AK, Fretzel S, Zurini M, Schnell L, Oertle T, Schwab ME (2003) Anti Nogo-A antibody infusion 24 hours after experimental stroke improved behavioral outcome and corticospinal plasticity in normotensive and spontaneously hypertensive rats. J Cereb Blood Flow Metab 23:154-165.

Whishaw IQ, Kolb B (1988) Sparing of skilled forelimb reaching and corticospinal projections after neonatal motor cortex removal or hemidecortication in the rat: support for the Kennard doctrine. Brain Res 451:97-114.

Z'Graggen WJ, Metz GAS, Kartje GL, Thallmair M, Schwab ME (1998) Functional recovery and enhanced corticofugal plasticity after unilateral pyramidal tract lesion and blockade of myelin-associated neurite growth inhibitors in adult rats. J Neurosci 18:4744-4757.

Z'Graggen WJ, Fouad K, Rainteau O, Metz GAS, Schwab ME, Kartje GL (2000) Compensatory sprouting and impulse rerouting after unilateral pyramidal tract lesion in neonatal rats. J Neurosci 20:6561-6569. 